\title{
Design and Evaluation of a Greenhouse Interface for Climate Control Programming and Networking
}

\author{
G. Diaz, S.F. Kelly and I. Yildiz \\ Department of Bioresource and Agricultural Engineering \\ California Polytechnic State University \\ San Luis Obispo, CA \\ USA
}

Keywords: controlled environment agriculture, climate control, programmable logic controllers, sensors

\begin{abstract}
At CalPoly the motto is "Learn by Doing". In the College of Agriculture, this is especially true and many of the labs provide an opportunity for students to implement this philosophy. Updated climate controls were installed in a series of greenhouses on the top floor of the Agricultural Science building that are used for student and faculty research projects. A Programmable Logic Controller (PLC) was installed to actuate the various vents, shading, heating, cooling and irrigation. A control program was developed to control and log temperatures and other operating parameters to monitor the greenhouse. An easy to use computer program was developed that is able to be accessed from a network web site. Implementation of this interface allows students and faculty to carry out projects and to keep accurate records of the environmental conditions affecting their research. The program emulates the previous control system so that it will be easy to use, but also offers other options not available before. This greenhouse allows for engineering students to develop additional control programs and gives them hands on experience and insight into their operation and function.
\end{abstract}

\section{INTRODUCTION}

Factors that can affect a greenhouse environment include temperature, light and humidity. These factors are affected by solar radiation and heat loss/gain (Aldrich, 1989). Greenhouse automation and control can improve energy efficiencies, increase production and decrease $\mathrm{CO}_{2}$ emissions (Baille, 2001; De Cock and VanLierde, 2000). Since different crops that are grown according to the requirements of the experiments being conducted, these factors need to be manipulated with some degree of complexity. Tools for teaching and demonstrating climate control techniques in greenhouse environment are vital for promoting and developing these energy saving technologies. Web based remote control of greenhouse automation using a scale model has been used to teach climate control techniques (Guzman et al., 2005).

PLCs were developed to support the automotive manufacturing industry in the early 1970s as a means of providing multiple input and output arrangements that could be used as a real time system since output results must be produced in immediate response to input conditions (Hartman, 2001). PLCs are now used in various engineering applications from plant management to fluid flow control. PLCs differ from regular computers because they are suited for severe environmental conditions. When a program is developed for a PLC, decision making logic is expressed in ladder logic, which is a method of drawing electrical logic schematics. Originally invented to describe relay logic, it uses two vertical rails and a series of horizontal rungs that resembles a ladder (Mintchell, 1998). PLCs need to interact with people in order to configure, report alarms or control. For this task a Human Machine Interface (HMI) is employed. The HMI should be designed to communicate effectively and simply and be intuitive (Haley, 2005).

The objective of this project was to develop a control program to control and log temperatures and other operating parameters to monitor a working greenhouse using a PLC. An easy to use computer program was developed that is able to be accessed from a 
network web site. Implementation of this interface allows students and faculty to carry out projects and to keep accurate records of the environmental conditions affecting their research. Once programmed and interfaced the system will be able to be remotely monitored and adjusted accordingly over the Internet. Data recorded such as temperature, humidity and moisture was logged and be accessible to be interpreted remotely as well.

\section{MATERIALS AND METHODS}

The NRM (Natural Resources Management) greenhouse laboratory is located in building 11 on the Cal Poly Campus in San Luis Obispo, CA (Fig. 1). It is currently used for conducting experiments by students. In an effort to update this facility, several senior projects in the Bioresource and Agricultural Engineering Department (BRAE) have been undertaken to update the environmental controls for this greenhouse lab. The installation of the hardware for the update was completed and is ready for programming and creating control algorithms.

Sensors were installed for temperature, humidity, daylight and moisture. They communicate with the Programmable Logic Controller (PLC) that was installed to provide environmental control and irrigation scheduling. This particular PLC is a SCADAPAK 32 (Control Microsystems, Kanata, Ontario, Canada) and is capable of expandability for future controls (Fig. 2). New wiring to all the components was installed throughout the greenhouse to increase the dependability of the system. The entire system was tested in previous senior projects and is currently operating by manual control.

In order to operate the system remotely the PLC was set up to communicate through an IP address. This was accomplished by physically connecting the PLC to a PC that has TelePace (Automation Direct, 2007) installed on it. The physical connection was made with a serial cable. The administrator provided IP address was put into the TelePACE software then loaded into the PLC.

\section{RESULTS AND DISCUSSION}

The greenhouse environmental control project has been used as a platform in several classes at CalPoly where students can get hands on experience in design and programming a greenhouse environmental control system. The system may be programmed remotely over the internet and immediate results of program or parameter changes may be seen almost instantaneously. Students have the opportunity to visit the greenhouse and see the results of their control algorithms.

An example of a simple task to be undertaken by the student is described as follows. A simple on/off ladder logic program was created on TelePace to operate the fan. This was done to check that the Internet connection was working and provide a simple test for correct programming. The next step was to create a virtual switch in Lookout. This can be a simple on/off type of switch. Once this task was accomplished, the entire sequence was tested to see that the algorithm and virtual switch are working properly. Once satisfied with the result of testing, a ladder logic program was created to link the inputs and outputs to the PLC. This was a complex task and involved some intuitive thinking to make sure that the sensors would not continuously cause the switches to cycle on and off. A simple on/off controller was programmed at the onset. Programming set points that can be adjusted enable the environment of the greenhouse temperatures to ramp up or down without spikes or oscillations. Further experimentation using PI and PID control algorithms are possible as well was observing the result of their algorithm on humidity.

The HMI program (Lookout Ver. 6.1, National Instruments, 2007) was used to create screens to organize the operation of the system. The HMI is used to navigate through the program to monitor, operate and create set points remotely. A hierarchy for different levels of security was created due to fact that many users will have access to the system. Typical examples are:

- Students needing historical data for projects;

- Technicians monitoring the greenhouse; 
- Technicians adjusting environment due to weather conditions;

- Emergency shut downs.

Once the security hierarchy was developed, screens were created to allow different levels of access. The typical method for accessibility is password driven. Monitoring the data will be the lowest security and will not need a password. Other levels can only be accessed with the proper password.

\section{CONCLUSION}

Agriculture is seeing an increased need for application of automation, computers and controls. There is also a real need for engineering students to understand, specify and design computer controlled equipment. This greenhouse environmental control project has been used as a platform where students can get hands on experience in design and programming a greenhouse environmental control system. The system may be programmed remotely over the internet and immediate results of program or parameter changes may be seen almost instantaneously. A control system was designed and programmed to control and acquire data. An HMI was developed to monitor and change temperature setpoints remotely using an internet connection.

\section{Literature Cited}

Aldrich, R.A. 1989. Greenhouse engineering. Northeast Regional Agricultural Engineering Service, Ithaca, New York.

Baille, A. 2001. Trends in greenhouse technology for improved climate control in mild winter climates. Acta Hort. 559:161-168.

Cleaveland, P. 2006. Ensuring a Safe, Secure HMI. Control Engineering 53(10):60-64.

De Cock, L. and Van Lierde, D. 2000. Evaluation of energy efficiency indicators in Belgian greenhouse horticulture. Acta Hort. 519:199-206.

Guzmán, J.L.M., Berenguel, F., Rodríguez and Dormido, S. 2005. Web-based remote control laboratory using a greenhouse scale model. Computer Applications in Engineering Education 13(2):110-124.

Haley, R. and Kuehl, S. 2005. Four steps to HMI screen design. Control Engineering, 52(11): 110 .

Mintchell, G.A. 1998. Relay ladder logic. Control Engineering 45(6):160.

National Instruments. 1996. Getting started with lookout. national instruments corporation. 11500 North Mopac Expressway, Austin, Texas 78759-3504.

National Instruments. 1996. Lookout developer's manual. national instruments corporation. 11500 North Mopac Expressway, Austin, Texas 78759-3504.

Rusin, T. and Kumm, J.J. 2006. SCADA from scratch in just 17 months. Transmission \& Distribution World 58(6):44-49.

Siemens, H.W. 2001. Evolution: RTUs and PLCs. Electrical World 215(3):72.

TelePace Ladder Logic, Reference and User Manual. Control Microsytems. 28 Steacie Drive, Kanata, Ontario, Canada. 


\section{Figures}

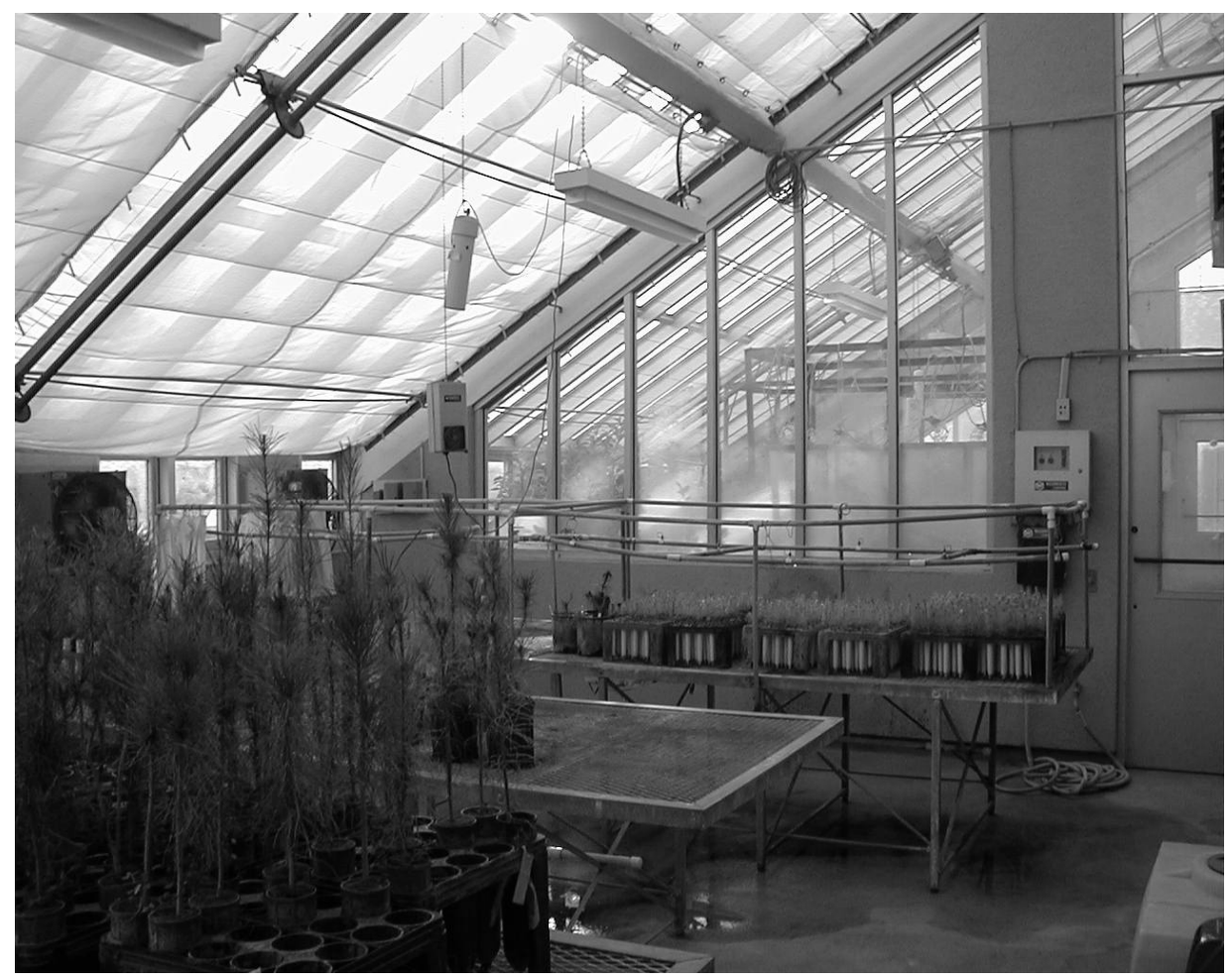

Fig. 1. NRM Greenhouse Lab.

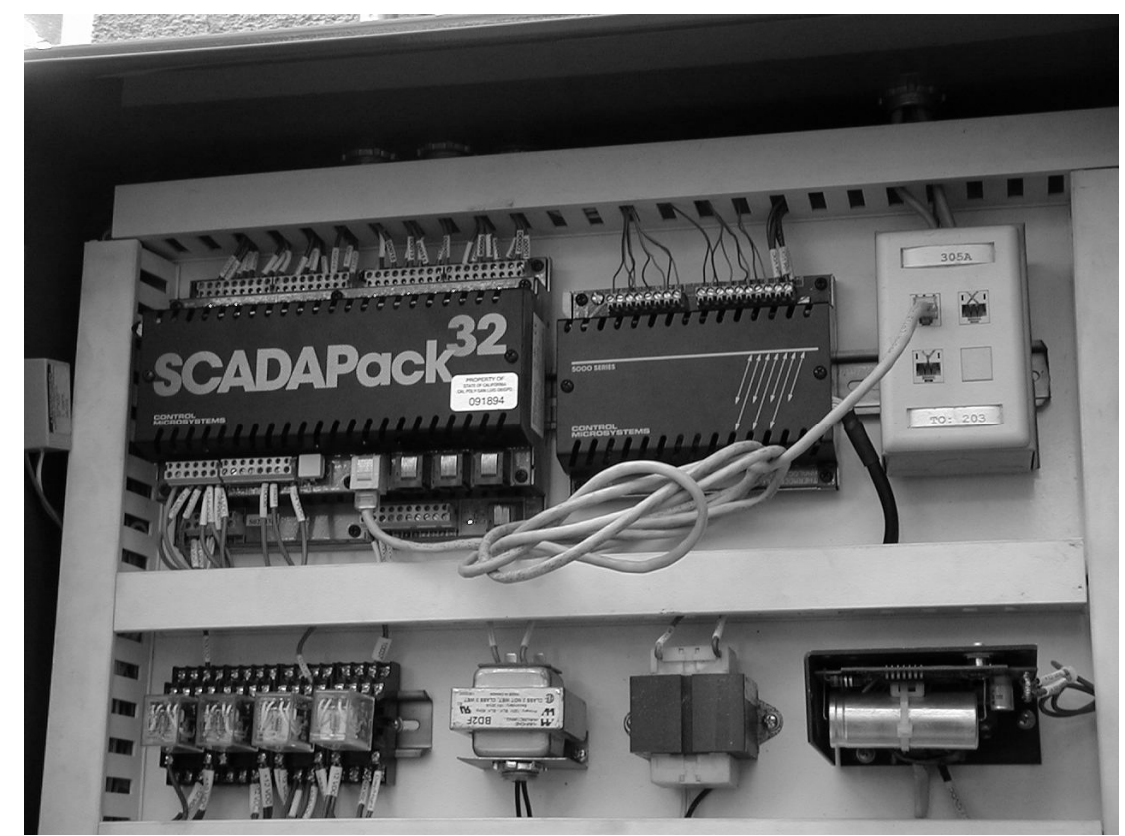

Fig. 2. SCADAPack 32 and auxiliary components. 